RESEARCH ARTICLE

\title{
Vitamins and Provitamins Intake as New Insights to Prevent and/or to Treat breast Cancer: A Systemic Review
}

\author{
Laya $A^{1,2^{*}}$, Koubala $B B^{2,3}$, Pathak $K P^{4}$ and Bueno $V^{5}$ \\ ${ }^{1}$ Department of Biological Sciences, Faculty of Science, University of Maroua, Cameroon \\ ${ }^{2}$ Department of Life and Earth Sciences, Higher Teacher's Training College of Maroua, University of Maroua, Cameroon \\ ${ }^{3}$ Department of Chemistry, Faculty of Science, University of Maroua, Cameroon \\ ${ }^{4}$ Faculty of Social Science, Nepal Open University, Nepal \\ ${ }^{5}$ Center for the Study of Aging, Escola Paulista de Medicina, Universidade Federal de São Paulo, Brazil \\ *Corresponding author: Laya A, Department of Biological Sciences, Faculty of Science, University of \\ Maroua, P.O. Box 46 Maroua, Cameroon, Tel: (+237)-653759511
}

\begin{abstract}
Female Breast Cancer (BC) is the most diagnosed cancer across the world. The present systematic review aimed to update the new insights of vitamins and provitamins to prevent and/or to treat BC. Vitamins and provitamins are natural products that have been implicated to prevent and to treat BC. However, it is still scarce and non-consensual as reported in the literature. A systematic literature review was conducted to identify studies through PubMed, Medline, and AMBASE up to June 27, 2021 solely on the association between vitamins (or provitamins) and $\mathrm{BC}$ prevention or treatment. The related grey literature also was used. The results of 127 revelant publications after exclusion of 7715 papers revealed that natural vitamins and provitamis were used to prevent or to treat BC. It has been clear evidence that vitamins and provitamins reduce the risk of $\mathrm{BC}$, which acting by various mechanisms with significant inverse effect and effective use in the treatment of BC. There is no indication for publication bias found, however there was high heterogeneity among studies. Despite its limitations, our systematic review provide the most comprehensive studies updated summary evidence to date on the association betweenvitamins, provitamins and $\mathrm{BC}$ prevention, treatment or therapeutic issues. The natural dietary of these nutrients may be encouraged among population in order to reduce the risk of $\mathrm{BC}$. Thus, we hope that our publication will help for further investigation such as a large clinical trials to confirm the findings of the present study.
\end{abstract}

\section{Keywords}

Breast cancer, Vitamins, Provitamins, Mechanism, Prevention

\section{Introduction}

In the last decades, the World Health Organization states that cancer is the second leading cause of death worldwide among noncommunicable diseases. Worldwide, an estimated number of 19.3 million new cancer cases (18.1 million without skin cancer) occurred in 2020 [1]. The global cancer burden is expected to be around 28.4 million cases in 2040, hence as a $47 \%$ rise from 2020. Female Breast Cancer (BC) is the most common diagnosed cancer and surpassed lung cancer, with an estimated over 2.3 million new cases (11.7\%) and with $6.9 \%$ deaths [1]. To date, almost more than two of every five people can be develop cancer in their lifetime. The consumption of dietary modifications are one of the most promising lifestyle changes that can adjust the risk of developing cancer from human by nearly $40 \%$ [2] and for this reason the diet-cancer linkages was studied over the past decades [3]. These studies have been showed high link with nutrients quality ingested by human. Thus, numerous studies have identified some bioactive nutrients to prevent or to reduce risk of certain types of cancers during the life [4-8]. This suggest that agood diet, rich in fruits and vegetables which contain bioactive nutrients, is significant in the prevention of cancer development, which is in agreement with a large number of scientific papers identifying a range of bioactive compounds

Citation: Laya A, Koubala BB, Pathak KP, Bueno V (2021) Vitamins and Provitamins Intake as New Insights to Prevent and/or to Treat breast Cancer: A Systemic Review. Int J Cancer Clin Res 8:162. doi. org/10.23937/2378-3419/1410162

Accepted: November 08, 2021: Published: November 10, 2021

Copyright: (C) 2021 Laya A, et al. This is an open-access article distributed under the terms of the Creative Commons Attribution License, which permits unrestricted use, distribution, and reproduction in any medium, provided the original author and source are credited. 
to prevent cancer. Certain nutrients such as vitamins, minerals, peptides, fatty acids, phenolics, and fibres may affect DNA repair, inflammation and hormones and growth factors via regulation of gene expression as well as the association to the antioxidant properties and improvement of the immune response. Particulary, epidemiological studies have correlated diet with cancer incidence and aggressiveness in many centruries $[8,9]$. Among these studies, vitamins and provitamins have been associated with a protective effect on cancer incidence in relation with lifestyle [10-14]. Fact, vitamins are organic compounds derived from plants and animals as well, however, provitamin A for example, are only synthetized in plants suggest that they need to obtain cartenoid from their diets. Vitamins and provitamins have been implicated to prevent and to treat cancer by the mechanisms of pathways involving cell growth, death and antioxidant properties as well [15-17]. However, the efficiency of effect of vitamins or provitamins may differ accordinaly the stage and type of cancer as well as mechanism involving in respect with age, race and other factors as well. Therefore, individual or synergism effect of the bioactive nutrients also may be potentially important in cancer-related prevention and treatment. While, many of studies showed some conflicting and/or inconlusive findings [18-21], which may be link to the methods or vitamins sources used in the study as well as race, age, menopausal status (premenopause and post-menopause) and the number of patients considered in differents studies.

In this systematic review, we aimed to summarize the most up-to-date the relevant papers on multiple role of different vitamins and provitamins to prevent and to treat $\mathrm{BC}$ incidence and progression, with special attention to natural vitamins/provitamins. Hence, we would highlight the associations between vitamins/ provitamins intake and breast cancer prevention and treatment, which shows insight into the comprehensive understanding of food quality intake as well as association with BC. This study also provides the comprehensive perspective for innovation and mechanism of dietary therapy and prevention of BC patients.

\section{Materials and Methods}

A literature research was conducted by utilising Google Scholar, PubMed, Medline, Scopus databases and liberay sources by selecting the terminologies "Breast cancer, prevention and treatment of Breast cancer", "Breast cancer and vitamins/provitamins","tumor", "mammary glands","angiogenesis", "Breast cancer control" etc. We searched for meta-analysis, pooled analyses, epidemiological studies, systematic reviews, prospective cohort studies, qualitative reviews andclinical studies evaluating the association between bioactive nutrients (vitamins and provitamins) and BC up until June 27, 2021. The search was not restricted by study design, and both peer-reviewed and grey literature were included. We searched some related grey literature from American Society of Clinical Oncology (ASCO), European Society of Medical Oncology (ESMO), and American Urological Association (AUA). When a large cohort study conducted after a meta-analysis was found, it was also used. Parameters used were only vitamins or provitamins ( $A$ and $D$ ) for prevention or treatment of BC.

We excluded studies that were not written on the $\mathrm{BC}$ and prevention or treatment and synthetic vitamins as well. Only the papers need to do focus on the association between vitamins/provitamins and breast cancer. Duplicate publications were deleted and title and abstract were checked for revelance. We found more than Seven thousand eighty huncdred and fiftytwo (7852) papers and after removal of those (7715) not meet our criteria after abstract and full text review, only one hundred and twenty seven (127) revelants publications among them as a selective compilation of approches and methodologies for our study.

\section{Dietary Source of Vitamins and Provitamins}

\section{Dietary source of vitamins}

This part was include in the present systematic review in order to know different sources of all vitamins or provitamins used by human in their diet. Vitamins are known as an essential compounds for the normal functioning and development of the human body. These substances are classified in two classes, fat-soluble and water-soluble and act as important antioxidant compounds. Vitamin $A$ is a fat-soluble found naturally in animal and their products [22]. It is all-trans retinol, which is an isoprenoid side chain found in animal tissue [23]. Vitamin D (active form: 1,25-dihydroxyvitamin D) was synthetized in the skin from a cholesterol like precursor (7-dehydrocholesterol) by exposure to sunlight or can be provided from animal products [2426]. There are 7 different types of vitamin D, however, only two major forms, D2 and D3 which are showed important role in human body $[26,27]$.

Vitamin $E$ is a fat-soluble found in a wide variety of plants such as vegetables and fruits, animal or their products, however, the main source is the plant oil $[27,28]$. Tocopherols and tocotrienols are the two part of vitamin $\mathrm{E}$ compounds which differ in their saturation state of isoprenoid side chain $[28,29]$ which confer high antioxidant activity. However, their concentrations vary within the variety and plant specices. The vitamin $C$ is a water-soluble nutrients found mainly in fruits, vegetables and in small quantity in animal products [30]. Vitamin C is another important antioxidant used in huaman diet. Vitamins $B$ are common micronutrients found in vegetables, fruits or in algae and edible mushrooms [31,32]. These vitamins are also found in animal products and some of them in yeasts as well. Vitamin $\mathrm{K}$ is also a fat-soluble nutrient, found in plant 
vegetables, plant oil and in small amount in animal products $[33,34]$.

\section{Dietary Source of provitamin A and D}

Provitamin $A$ and $D$ are all fat-soluble nutrients found both plants and animals or their products acting as important natural antioxidants. Provitamin A provided from carotenoids which are pigments universally synthesized by all terrestrial and aquatic photoautotrophs, including plants, algae, some nonphotosynthetic bacteria, some insects, and some fungi [35]. The structure of carotenoids is based on a C40 isoprenoid backbone that may be acyclic or modified to have one or both ends modified into rings with diverse structural modifications [3]. Lycopene, $\beta$-carotene, $\alpha$-carotene, lutein, zeaxanthin, and $\beta$-cryptoxanthin are the most common carotenoids in human serum, however, only $\beta$-carotene, $\alpha$-carotene and $\beta$-cryptoxanthin are the sources of provitamin $A$, therefore the most common precursors of vitamin $A$. Provitamin A refers to those carotenoid precursors that are biologically active as retinol.

Provitamin $D$ are resulting of the synthetized of vitamin $\mathrm{D}$ by microalgae and wild mushrooms. These forms are ergosterol (vitamin D2) which can be found in wild mushrooms, and ultraviolet-B (UVB) exposed fungi and yeast [36], 7-dehydrocholesterol in order to synthesize vitamin D3 by UVB exposure [37]. Provitamin D3 was syntheized only in microalgae [36].

\section{Preventionand treatment of breast cancer}

Vitamin A: BC remains the most common tumor found in women and one of the three most common cancers worldwide in the last years [38,39]. Natural vitamin A, or an All-Trans Retenoic Acids (ATRA), the active metabolite of vitamin $A$ are used to prevent and to treat $B C$ acting by many molecular mechanisms as described in different studies. Vitamin A acts by promoting the apoptosis and inhibiting angiogenesis of human BC cells or impact as antioxidant by scavenging free radicals. In line of prevention, Kim, et al. [40] found in their study, serum vitamin A levels and their relationships with other biomarkers in Korean $B C$ patients that the serum concentration of vitamin A was associated with a seven-fold decrease in risk of benign breast disease and a six-fold decrease in risk of BC. Their results were consistent with some researchers who reported also a high reduced risk association of $B C$ with vitamin A or provitamin A $[41,40]$. While, the molecular mechanism of vitamin $A$ against breast cancer is variable and some were described by many researchers such as Mangiarotti, et al. [42] and Wu, et al. [43], who reported that ATRA induces re-differentiation of transformed cells during the early stages of the neoplastic process and promotes the apoptosis of human BC cells by regulating the Tet Methylcytosine Dioxygenase 2-Protein Kinase $C$ zeta (TET2-PKC) pathway. Fact, the apoptose was the one mechanism known to be induced as reported by Bernardo, et al. [44] who observed that the pro-apoptotic signaling induced by retinoic acid and dsRNA was under the control of interferon regulatory factor- 3 in $B C$ cells which may lead to the death of tumor. For instance, in retinoid-sensitive cell-lines and tumors, ATRA stimulated a viral-mimicry response involving the activation of the interferon (IFN) and antigen-presentation pathways as well as other biological processes controlling the sensitivity of tumors to immune checkpoint inhibitors [45]. Further, retinoic acid may inhibit telomerase activation through inducing histone deacetylation in estrogen receptor-negative BCcells for deaths [46]. Furthermore, retinoic acid can impair estrogen signaling in $\mathrm{BC}$ cells by interfering with the activation of LSD1 via protein kinase $A$ and may inhibit aromatase activation and expression, which indicates that the estrogen supply inside BC cells is insufficient to maintain cancer cell growth $[47,48]$. Hence, the vitamin A suggesting as important to be used for reducing risk of $\mathrm{BC}$ as well as to treat $\mathrm{BC}$, however further molecular investigation will be done to confirm the findings for the effective therapy.

Provitamin A: The provitamin A are mainly provided from $\beta$-carotene, $\alpha$-carotene and $\beta$-cryptoxanthin, however, some carotenoids such as lutein, for example, selectively induced apoptosis in MCF-7 BC cells but not in normal human mammary cells [49]. It was reported that $\beta$-carotene (provitamin $A$ ), at the physiologically concentration of just $1 \mu \mathrm{M}$, can decrease the expression of Bcl-2 and PARP, and NF-kB in human BC MCF-7 cells [50] by inhibiting the genes regulation of hormone involved in proliferation of cells. Fact, $\beta$-carotene treatments can also inhibit the activation of Akt and Erk1/2, subsequently decreasing phosphorylation of $\mathrm{Bad}$ and downregulate superoxide dismutase-2 (Sod-2, an antioxidant enzyme), its transactivation factor Nrf2, and Endoplasmic Reticulum (ER) stress marker X-box Binding Protein 1 (XBP-1) levels [51]. Several lines of evidence suggest that carotenoids such as lycopene, $\beta$-carotene, lutein, and astaxanthin have the ability to modulate the NF-KB pathway, in some cases by inhibiting cancer cell growth via NF-KB pathway [52-54].

Some studies carried out such as in a pooled analysis of eight cohort studies comprising 3055 cases of BC and 3956 control subjects, showed a statistically significant inverse association which was observed between $B C$ and levels of plasma/serum provitamin A ( $\alpha$-carotene, $\beta$-carotene) and lutein + zeaxanthin, lycopene, and total carotenoids [51,55]. This inverse association was strong for some receptors such as estrogen receptor-negative (ER-) compared to ER + tumors [56]. Another systematic review and meta-analysis of eight cohorts, one clinical trial, and one pooled study, comprising 19,450 BC case, dietary intake of $\beta$-carotene was significantly associated with improved BC survival (RR of 0.70) [57]. The provitamin A can act also as antioxidant because 
having the ability to scavenge ROS molecules which can induce the lyse of $B C$ line $[58,59]$, thus reduce DNA damage in cancerous tissues in human patients. For instance, a study has shown that addition of lutein and $\beta$-carotene to ROS-inducing doxorubicin at a low dose of 0.2-3.2 $\mu \mathrm{M}$ is effective against BC cell lines MCF-7 and MDA-MB-231 without influencing the redox status (lipid peroxides (LPX), sothe ROS, and lactate dehydrogenase levels) in normal breast epithelial MCF 10A cells [60]. Bohlke, et al. [61] reported also in a case-control study in Greece, included eight hundred and twenty women with histologically confirmed BC were compared with 1548 control women, among premenopausal women, provitamin A ( $\beta$-carotene) was inversely associated with $B C$ risk. Fulan, et al. [62] indicated that both the total intake of vitamin $A$ and retinol could reduce $B C$ risk. In addition, Bakker, et al. [63] found in a nested casecontrol study within the european prospective that high concentration of plasma provitamin $A$ ( $\beta$-carotene and $\alpha$-carotene) are associated with low BC risk of ERtumors. During their study, an investigation into Cancer and Nutrition cohort, 1502 female incident BC case was included, with an over sampling of premenopausal ( $n=582$ ) and estrogen receptor-negative (ER-) cases ( $n=462$ ). Provitamin $A$ is one the best antioxidant compounds that had different mechanisms to inhibit proliferation of cell tumor or to induce apopotosis of BC.

Vitamin K: The different forms of Vitamin $\mathrm{K}$ has been proved to have a negative effect on BC in many studies, which was shown by both in vitro and in vivo studies $[35,36]$. Vitamin $\mathrm{K}$ can act in different pathways mechanism signals which consists of the production of ROS, via the 1-electron cycling of the quinone as well as by the oxidative capacity of the cell is exceeded by the increased redox-cycling of menadione and the production of ROS, resulting in its death $[64,65]$. Secondly, the mechanism is linked on cell cycle arrest and apoptosis induced by modulation of transcription factors, and finally the deaths of cell lines [66]. Noto, et al. [67] found in their study that vitamin $\mathrm{K} 3(13.8 \mu \mathrm{g} /$ $\mathrm{mL}$ ) produced a $50 \%$ inhibition of $\mathrm{BC}$ cell lines and, when combined with vitamin C $(99.01 \mu \mathrm{g} / \mathrm{mL}), \mathrm{K} 3(1.38 \mu \mathrm{g} / \mathrm{mL})$ increased inhibition by $74 \%$ suggesting their synergism to inhibit. It was demonstrated also that, when both vitamin C and K3 concentrations were increased (104 $\mu \mathrm{mol} / \mathrm{L}$ and $105 \mathrm{nmol} / \mathrm{L}$, respectively), a high effect was observed with a 93\% inhibition [67]. Also, Miyazawa, et al. [68] found that vitamin K2 induced non-apoptotic cell death along with autophagy, in triple negative $B C$ cell lines. However, cell death phenotype induced by vitamin K2 appears to differ among the type of cancers suggesting the possibility of using vitamin $\mathrm{K} 2$ for the $\mathrm{BC}$ therapy and prevention without side effects as reported for conventional drug.

Vitamin C: Consumption of vitamin C is very important for our body and lower consumption of vitamin $\mathrm{C}$ might increase $\mathrm{BC}$ risk. Fact, vitamin $\mathrm{C}$ acts as antioxidants and by many pathways molecular machanisms to be effective as anticancer. For example, Zasowska-Nowak, et al. [17] observedan effect of high-dose vitamin $C$ in advanced-stage cancer patients and found that vitamin $C$ is effective against $B C$ in all stages, however this can be varied with age or race. Vitamin $C$ can generate the cell cycle arrest, caspase-independent autophagy mediated by beclin-1 and LC3 II, apoptosis via induction of apoptosis-inducing factor, induction of oxidative DNA damage, apoptosis mediated by Bax protein signalling, release of cytochrome $\mathrm{C}$ from mitochondria, activation of caspase 9 and caspase 3, and cleavage of poly [ADPribose] polymerase in a ROS-dependent manner. Gan, et al. [69] reported that the vitamin $C$ inhibits TNBC (Triple Negative Breast Cancer) metastasis by acting the expression of SYNPO2 and YAP1 and therefore vitamin $\mathrm{C}$ may thus have a potential role in the prevention and treatment of TNBC metastasis. Vollbracht, et al. [70] found that the administration of vitamin $\mathrm{C}$ with standard anti-cancer therapy in the first postoperative year of women with $\mathrm{BC}$ resulted in significantly enhanced performance status and reduction of complaints induced by the disease and chemo-radiotherapy. Similarly, the positive impact of high-dose vitamin C on patients' performance status was also reported by the same author in the epidemiological retrospective study with 125 women with primary non-metastasized $\mathrm{BC}$, receiving a basic anti-tumor therapy with vitamin $C$ at a dose of $7.5 \mathrm{~g}$ once a week for at least 4 weeks. Women who received vitamin $C$ had a significantly better performance status during adjuvant therapy and the aftercare follow-up than those who did not receive vitamin C. Carr, et al. [71] reported two case studies demonstrating improvement in a control of pain after administration of vitamin $C$ therapy for four weeks in women with BC. In the same way, Zeng, et al. [72] found that high-dose vitamin $C$ inhibits cell migration and invasion of $\mathrm{BC}$ cell lines through suppressing epithelialmesenchymal transition. Harris, et al. [73] found in their meta-analysis that post-diagnosis vitamin C supplement use was associated with a reduced risk of mortality as well as dietary vitamin C intake was significantly associated with a reduced risk of total mortality and BC specific mortality. Furthermore, Bohlke, et al. [61] reported in a case-control study in Greece, included eight hundred and twenty women with histologically confirmed BC were compared with 1548 control women, among premenopausal women, vitamin $\mathrm{C}$ was inversely associated with BC risk. Recently, Zhang, et al. [74] found that high vitamin $C$ intake is significantly associated with reduced $\mathrm{BC}$ incidence and mortality. Thus, it may be considered as an anticancer nutrient for $\mathrm{BC}$ patients.

Vitamin E: The experimental model studies in vitro and in vivo conducted by Afam, et al. [75] had shown such as antioxidative, pro-antioxidative, anti-inflammatory, modulation of cell signaling, antiproliferation, 
antiangiogenesis, and apoptosis induction effects of vitamin $E$ as well. Vitamin $E$ had first acted as a non-antioxidant, $\alpha$-tocopherol had inhibited muscle proliferation activity and protein kinase C activity [4]. Jiang [76] reported that Vitamin E ( $\alpha$-tocopherol) was used to inhibit cancer promoting pathways, including cyclooxygenase and 6-lipoxygenase eicosanoids, NFKB and signal transducer and activator of transcription factor. The reduced activity of protein kinase $B$ and of NF-kB was shown to mediate tocotrienol reduced mammalian cancer cell proliferation [77]. Ripon, et al. [4] found an inverse association between vitamin $E$ and $B C$ which was exhibited to be a major difference in serum vitamin $E$ levels and the consumption of vitamin $E$ in cases orcontrols. Fact, vitamin $E$ supplementation inhibited mammal's tumor cell proliferation and induced cell death in a dose responsive manner [78-80]. Kline, et al. [81] reported that vitamin $\mathrm{E}$ forms can induce $\mathrm{BC}$ cells to undergo apoptosis. Malafa and Neitzel [82] found also that the vitamin $\mathrm{E}$ inhibits the growth of $\mathrm{BC}$ cells in vitro and in vivo. In additon, serum concentrations of vitamins $E$ was significantly lower in Korean BC patients and in benign breast disease patients than in healthy controls [42]. Vitamin E is potentially used for the treatment of $\mathrm{BC}$ in women as a chemotherapeutic agent [78-80,83,84]. Morever, Abraham, et al. [85] stated that vitamin $E$ is linked with an inverse effect on $B C$ suggesting vitamin $E$ can delays $B C$ risks or use for its treatment. Also, Lajous, et al. [86] reported that high folate intake was associated with decreased $B C$ risk which was in agreement with $\mathrm{Hu}$, et al. [87] who found that severe $\alpha$-tocopherol deficiency could increase BC risk.

Torun, et al. [88] found a decreased serum levels of vitamin $\mathrm{E}$ in $\mathrm{BC}$ patients compared to controls suggesting the important role vitamin $E$ for prevention from BC. Hence, Ben-Chioma and Elekima [89] propsed that the $B C$ patients had reduced level of vitamin $E$ suggests the possible risk of BC. Turley, et al. [90] stated that vitamin $\mathrm{E}$ may be of clinical use in the treatment of aggressive human BC, particularly those that are refractory to antiestrogen therapy. Other studies give evidence of a general inhibition of cell proliferation by dl- $\alpha$-tocopherol, with breast [91]. Bohlke, et al. [61] reported in a case-control study in Greece, included eight hundred and twenty women with histologically confirmed BC were compared with 1548 control women, among premenopausal women, vitamin $E$ was inversely associated with BC risk. Recent study of Godazandeh, et al. [92] demonstrated that for the treatment, vitamin Ecould be effective in breast painrelieving and decreasing nodularity with minimal side effects in comparaison with drugs. Vitamin $E$ may inhibit the cancer formation by acting as antioxidant (quenching of free radicals) or by direct influences on tumor cells by reducing the tumor growth by induction of differentiation as well as cell cycle inhibition of apoptosis and elimination of tumor cells especially when the reinforcement of the immune system is induced. Thus, an advantage for using vitamin $\mathrm{E}$ in human cancer therapy is high that lead to conclude that can be used to prevent $\mathrm{BC}$ and to treat as well by acting via apopotic activity as reported by Theriault, et al. [93]. Kilne, et al. [81].

Vitamin D: The vitamin D affects the cell cycle, apoptosis, hormone receptors, angiogenesis, and hypoxia, all of which are related to the BC growth, progression and metastasis [94]. Kim, et al. [42] found that severe vitamin $D$ deficiency was found more prevalent in BC patients of Korean women than in healthy controls. Similarly, vitamin D level was significantly lower in $\mathrm{BC}$ patients with estrogen receptor-negative or triplenegative subtypes than in those with other subtypes [42]. National Health and Nutrition Examination Survey Epidemiologic Follow-up Study, 1971-1975 to 1992 found that vitamin $D$ reduce the risk of $B C$ [95]. A trend toward cases of $\mathrm{BC}$ in woman with intakes of vitamin D above $400 \mathrm{IU}(10 \mu \mathrm{g}) /$ day was found associated with an $8 \%$ reduction in the risk of BC [65]. Shin, et al. [59] found also that vitamin D intake of 500 IU or more per day was associated with a significant $28 \%$ lower risk of BC in premenopausal women. Similarly, Yin, et al. [4] found in their meta-analysis, serum vitamin $D$ and $B C$ risk, that in case-control studies with measurement of $25(\mathrm{OH}) \mathrm{D}$ after diagnosis showed an inverse association which was consistent with the results of Garland, et al. [96] who found a $50 \%$ lower risk of BC associated with a serum $25(\mathrm{OH})$ D level P52 ng/mL, compared to 613 $\mathrm{ng} / \mathrm{mL}$ in their study by searching the Medline database for 1966-2006. Chen, et al. [97] found in their metaanalysis that there was a significant inverse relationship between vitamin D intake and BC risk, with an overall Relative Risk (RR) of high versus low vitamin $D$ intake for $\mathrm{BC}$ of 0.91 and the highest quantile of circulating 25 $(\mathrm{OH}) \mathrm{D}$ was found to be associated with a $45 \%$ decrease in $\mathrm{BC}$ when compared with the lowest quantile. Similar inverse association was obtained by Mohr, et al. [98] in their pooled analysis of 11 case-control studies that individuals in the highest quintile versus the lowest quintile of $25(\mathrm{OH}) \mathrm{D}$ concentrations had a reduction in $B C$ risk, in which serum $25(\mathrm{OH}) \mathrm{D}$ level of $47 \mathrm{ng} / \mathrm{mL}$ was associated with a $50 \%$ lower risk of BC. Also, an inverse association was found by Stoll, et al. [99] in their systematic review of 37 studies, by Shekarriz-Foumani, et al. [100] in their systematic review who reviewed (14) studies and found that serum $25(\mathrm{OH}) \mathrm{D}$ deficiency had been very prevalent among BC neoplasms. For BCcontrolled studies, case-control studies consistently find an inverse correlation between $25(\mathrm{OH}) \mathrm{D}$ and $\mathrm{BC}$ risk $[101,102]$. These studies suggest that elevated serum $25(\mathrm{OH}) \mathrm{D}$ through the sun exposure and dietary intake more than 400 IU per day vitamin D supplementation decreased BC risk and recurrence. Al-Azhri, et al. [103] concluded in their study that vitamin D3 treatment 
can be effective against aggressive BC. Many other researchers reported significant reduction risks as well as effective therapyof BC using vitamin D [9,94,104109]. Furthermore, meta-analyses of population studies demonstrate an inverse relationship between vitamin D status and BC risk [110] which is consistent with the results of Tavera-Mendoza, et al. [111] who reported a number of epidemiological studies had shown that sufficient vitamin $D$ serum levels might be protective against BC. Moreover, severe $25(\mathrm{OH})$ D deficiency was associated with aggressive behavior of BC [112] suggesting that low circulatory $25(\mathrm{OH})$ D could be associated with increased risk of BC. Fact, high blood 25 $(\mathrm{OH}) \mathrm{D}$ levels were significantly associated with lower BC mortality (pooled RR $1 \frac{1}{4}$ 0.58, 95\% Cl: 0.40-0.85) [109], and also high vitamin $D$ levels have been shown to be associated with increased survival in patients with $B C$ [113], however the mechanisms for vitamin D-mediated suppression of BC-relevant gene expression appear as being complex [114].

Vitamin D may exert antiproliferative, prodifferentiating, antiangiogenic and antimetastatic effects in BC cells, thus retards the development and growth of tumours as reported by Deeb, et al. [115] and Kulling, et al. [116]. Song, et al. [117] found in their study, vitamin D intake, blood vitamin D levels, and the risk of BC: A dose-response meta-analysis of observational studies that $\mathrm{BC}$ risk was inversely related to blood vitamin D levels. For Story [14], vitamin D in combination with Zinc and fatty acid ( $\omega-3$ PUFAs) would be ideal for treating BC. Mohr, et al. [98] reported that high serum $25(\mathrm{OH}) \mathrm{D}$ was associated with lower mortality from $B C$ suggest that the serum $25(\mathrm{OH}) D$ in all patients with BCcould be restored to the normal range (30-80 ng/ml). Janowsky, et al. [118] found a consistent data with a protective effect of 1,25-D for BC in white women suggesting in this a clinic-based case control study that race and age can affect significantly the results of study. Hossain, et al. [119] reported that $25(\mathrm{OH}) \mathrm{D}$ deficiency was directly related to $\mathrm{BC}$ and total vitamin D and supplemental vitamin D intakes had an inverse relationship with this outcome. Shirazi, et al. [120] in their study found that women with low levels of 250HD3, as compare to women in the middle tertile, had a high risk of breast tumours with an unfavourable prognosis. The circulating form of vitamin D may induce normal cellutar proliferation by regulating genes that control the mechanism and induce differenciation, apopotosis and inhibiting angiogenesis of cell cancer [121,122].

Vitamin B: Vitamins B (B6, B9 and B12) play important roles in nucleotide biosynthesis and biological methylation reactions, aberrancies of which have all been implicated in carcinogenesis [123] and vitamins B1 and B2 can inhibit inflammation as well. Fact, one-carbon metabolism, related $B$ vitamins (folate, thiamine, riboflavin, niacin, pantothenic acid, pyridoxine, cobalamin), comprises a complex network of biochemical pathways that donate methyl groups for many important biological processes [124]. Thus, many studies investigated the associations between $B$ vitamins and BC risk, however, mainly focusedonly on folate (vitamin B9), vitamin B6 and B12 [125]. For example, in China, Shrubsole, et al. [126] found in their study evidence of a decreased risk of BC associated with high consumption of folate among women who do not regularly consume alcohol suggesting alcohol may increase the risk of BC. Similar observation was done by $\mathrm{Xu}$, et al. [127], who found that higher dietary intake of vitamin B1 and B3 was associated with improved survival during the followup period. The meta-analysis of observational studies indicates also that vitamin B2 intake could decrease BC risk [128], however may vary with age. Razeghian, et al. [129] compared the levels of folic acid, B6, and B12 in the plasma of 85 people with $\mathrm{BC}$ were measured and compared with healthy people and found a significant inverse trend observed between folate intake and vitamin $\mathrm{B} 6$ intake and $\mathrm{BC}$ risk. Zeng, et al. [72] reported also that the folate intake decreases the risk of oestrogen receptor (ER) negative (-) and ER-/ progesterone receptor (PR)- BC, with pooled risk ratios of 0.88 [95\% confidence interval $(\mathrm{Cl}): 0.78-1.00$ ] and 0.82 (95\% Cl: 0.68-0.97), respectively and an increment of folate intake of $100 \mu \mathrm{g}$ per day was associated with a deceased risk of ERand ER-/PR-BC.

Similar case was reported by Ren, et al. [130] who found in their meta-analysis titled association of folate intake and plasma folate level with the risk of BC: $A$ dose-response meta-analysis of observational studies a high folate intake correlated with a low BC risk in premenopausal women. Recently, Egnell, et al. [131] found in their study that the dietary pyridoxine intakes were inversely associated with BC risk. In this way, total thiamin intake was borderline inversely associated with $\mathrm{BC}$ risk, so they concluded that their prospective cohort study suggesting pyridoxine and thiamin were inversely associated with $\mathrm{BC}$ risk. It was also reported that high plasma vitamin B6 and riboflavin lower BC risk, especially in premenopausal women [132]. In addition, Lurie, et al. [133] found that high circulating levels of vitamin $\mathrm{B} 6$ are associated with a reduced risk of invasive postmenopausal BC. Zhang, et al. [134] found also that folate and vitamin $\mathrm{B} 6$ have the potential to be chemopreventive against $\mathrm{BC}$ and that ensuring adequate circulating levels of folate and vitamin B6 by consuming foods that are rich in these nutrients. Shrubsole, et al. [135] reported that high intake of folate by Chinese women was associated with decreased BC risk. Furthermore, a randomized trial of combined folic acid, vitamin B6, and vitamin B12 revealed significantly reduced $B C$ risk among women in the treatment arm of older (> 65-years-old) [136]. Lin, et al. [137] found an evidence that high circulating concentrations of folate, vitamin B6, and vitamin B12 are associated with overall 
risk reduction of $\mathrm{BC}$ suggesting one-carbon metabolism may be an important pathway that could be targeted to improve BC survival. Another experimental study suggested that vitamin B6 exerts other anticarcinogenic effects by reducing cell proliferation, nitric oxide production and angiogenesis [138], and clinical studies provide evidence that vitamin B6 play a role in protection of BC [139]. Further large sample study are greatly needed to confirm their association [140]. Our study indicated that vitamins B have an important role in preventing or treating of $B C$ when taking by $B C$ patient.

\section{Limitations}

There are many limitations of this study. The different analyses of the data provided by the individual studies were limited and heterogenous. The results reported were differed from one to another with an estimation of risk may be less accurate than if individual data had been available. Authors used also different methods to evaluate inverse association between vitamins and breast cancer or to treat, which can affect the comparability of different studies linked with heterogeneity among studies and publications bias is impossible to be excluded when the number studies is low. In addation, missing relevant publications is possible, even if we searched via Medline, EMBASE, PubMed, etc.

\section{Conculsion}

The current review summarizes the available literature on the role of natural products, vitamins and provitamins to prevent and to treat BC. Data literature on $\mathrm{BC}$ associated with different were limited however, the findings of the present study indicated that natural vitamins and provitamins were inversely associated with risk of $B C$ and used for an effective therapy. The menopausal status, race, and age as well had effectiveness to prevent or to treat BC. These findings support some recommendations for increasing the intake of vitamins and provitamins in order to prevent BC. Some studies such as clinical trials in the future will be very importantin order to confirm the findings.

\section{Future Study}

Despite the extensive effort to understand the inverse relationship between vitamins or provitamins in breast cancer development, prevention and treatment, many issues remain unclear hence clinical trials will be needed.

\section{Funding Source}

This research did not receive any specific grant from funding agencies in the public, commercial, or not-forprofit sectors.

\section{Competing Interest Statement}

There are no conflict of interest for this paper.

\section{References}

1. Sung H, Ferlay J, Siegel RL, Laversanne M, Soerjomataram I, et al. (2021) Global Cancer Statistics 2020: GLOBOCAN Estimates of Incidence and Mortality Worldwide for 36 Cancers in 185 Countries. CA Cancer J Clin 71: 209-249.

2. Anand $P$, Kunnumakara $A B$, Sundaram $C$, Harikumar $K B$, Tharakan ST, et al. (2008) Cancer is a preventable disease that requires major lifestyle changes, Pharm Res 25: 20972116.

3. Rowles III, John W (2020) Carotenoids and their role in cancer prevention. BBA- Mol Cell Biol Lipids 1865: 158613.

4. Yin L, Grandi N, Raum E, Haug U, Arndt V, et al. (2010) Meta-analysis: Serum vitamin $D$ and breast cancer risk. Eur J Cancer 46: 2196-2205.

5. Cui J, Gong M, He Y, Li Q, He T, et al. (2016) All-trans retinoic acid inhibits proliferation, migration, invasion and induces di_erentiation of hepa1-6 cells through reversing EMT in vitro. Int J Oncol 48: 349-357.

6. Li Y, Zhang Y, Liu X, Wang M, Wang P, et al. (2018) Lutein inhibits proliferation, invasion and migration of hypoxic breast cancer cells via downregulation of HES1. Int J Oncol 52: 2119-2129.

7. Ripon MDSH, Habib MAH, Hossain M, Ahmed N, Kibria T, et al. (2020) Role of Vitamin E in Prevention of Breast Cancer: An Epidemiological Review. Asian J Adv ResReports 11: 37-47. Article no.AJARR.58489.

8. Suwannasom N, Kao I, Pruß A, Georgieva R, Bäumler H, et al. (2020) Riboflavin: The Health Benefits of a Forgotten Natural Vitamin. Int J Mol Sci 21: 950.

9. Kotepui M (2016) Diet and risk of breast cancer. Contemp Oncol (Pozn) 20: 13-19.

10. Freudenheim JL, Marshall JR, Vena JE, Laughlin R, Brasure JR, et al. (1996) Premenopausal breast cancer risk and intake of vegetables, fruits, and related nutrients. J Natl Cancer Inst 88: 340-348.

11. Dorgan JF, Sowell A, Swanson CA, Potischman N, Miller $R$, et al. (1998) Relationships of serum carotenoids, retinol, a-tocopherol, and selenium with breast cancer risk: Results from a prospective study in Columbia, Missouri (United States). Cancer Causes Control 9: 89-97.

12. Kiely M, Hodgins S J, Merrigan BA, Tormey S, Kiely PA, et al. (2015) Real-time cell analysis of the inhibitory effect of vitamin $\mathrm{K} 2$ on adhesion and proliferation of breast cancer cells. Nutr Res 35: 736-743.

13. Koklesova L, Alena Liskova A, Samec M, Zhai K, Abotaleb $M$, et al. (2020) Carotenoids in Cancer Metastasis-Status Quo and Outlook.Biomolecules 10: 1653.

14. Story MJ (2021) Essential sufficiency of zinc, u-3 polyunsaturated fatty acids, vitamin $D$ and magnesium for prevention and treatment of COVID-19, diabetes, cardiovascular diseases, lung diseases and cancer. Biochimie 187: 94-109.

15. Niranjana R, Gayathri SN, Mol T, et al. (2015) Carotenoids modulate the hallmarks of cancer cells. J Funct Foods 18: 968-985.

16. Carazo A, Macáková K, Matoušová K, Krčmová LK, Protti M, et al. (2021)Vitamin A Update: Forms, Sources, Kinetics, Detection, Function, Deficiency, Therapeutic Use and Toxicity. Nutrients 13: 1703.

17. Zasowska-Nowak A, Nowak PJ, Ciałkowska-Rysz A (2020) High-Dose Vitamin C in Advanced-Stage Cancer Patients. Nutrients 13: 735. 
18. Robien K, Cutler GJ, Lazovich D (2007) Vitamin D intake and breast cancer risk in postmenopausal women: the lowa women's health study. Cancer Causes Control 18: 775-782.

19. Kawase T, Matsuo K, Suzuki T, Hirose K, Hosono S, et al. (2010) Association between vitamin D and calcium intake and breast cancer risk according to menopausal status and receptor status in Japan. Cancer Sci 101: 1234-1240.

20. den Hollander P, Savage MI, Brown PH (2013) Targeted therapy for breast cancer prevention. Front Oncol 3: 250.

21. Fernandez-Lazaro $\mathrm{Cl}$, Romanos-Nanclares $\mathrm{AR}$, Sanchez-Bayona R, Gea A, Sayon-Orea C, et al. (2021) Dietary calcium, vitamin $\mathrm{D}$, and breast cancer risk in women: findings from the SUN cohort. Eur J Nutr 60: 3783-3797.

22. Rodriguez-Amaya DB (1997) Carotenoids and food preparation: the retention of provitamin $A$ carotenoids in prepared, processed, and stored foods. Arlington, John Snow and Opportunities for Micronutrient Interventions Project.

23. Olson JA, Vitamin A, In: Brown ML, et al. (1990) Present knowledge in nutrition. ( $6^{\text {th }}$ edn), Washington, DC: International Life Sciences Institute-Nutrition Foundation 96-107.

24. Feldman D, Glorieux FH, Pike JW, et al. (1997) Vitamin D. Academic, New York.

25. Nair R, Maseeh A (2012) Vitamin D: The "sunshine" vitamin. J Pharmacol Pharmaco Ther 3: 118-126.

26. Ljubic A, Jacobsen C, Holdt SL, Jakobsen J (2020) Microalgae Nannochloropsis oceanica as a future new natural source of vitamin D3. Food Chem 320: 126627.

27. Ravisankar P, Reddy A A, Nagalakshmi B, Koushik OS, Kumar BV, et al. (2015) The Comprehensive Review on Fat Soluble Vitamins. IOSR J Pharma 5: 12-28.

28. Laya A, Koubala BB (2020) Changes in Vitamin E and $\beta$-Carotene Contents in Various Edible Cassava Leaves (Manihot esculenta Crantz) of Different Ages across Multiple Seasons. Inter J Agro 8.

29. Gheorghe G, Stoian AP, Gaman MA, et al. (2019) The benefits and risks of antioxidant treatment in liver diseases. Rev Chim 70: 651-655.

30. Ferraro PM, Curhan GC, Gambaro G, Taylor EN (2016) Total, Dietary, and Supplemental Vitamin C Intake and Risk of Incident Kidney Stones. Am J Kidney Dis 67: 400-407.

31. Nakos M, Pepelanova I, Beutel S, Krings U, Berger RG, et al. (2017) Isolation and analysis of vitamin B-12 from plant samples. Food Chem 216: 301-308.

32. Zhao L, Zhao X, Xu Y, Liu X, Zhang J, et al (2020) Simultaneous determination of 49 amino acids, $B$ vitamins, flavonoids, and phenolic acids in commonly consumed vegetables by ultra-performance liquid chromatography-tandem mass spectrometry. Food Chem 344: 128712.

33. Kaneki M, Hosoi T, Ouchi Y, Orimo H (2006) Pleiotropic actions of vitamin $\mathrm{K}$ : Protector of bone health and beyond? Nutrition 22: 845-852.

34. Elder SJ, Haytowitz DB, Howe J, Peterson JW, Booth SL (2006) Vitamin K contents of meat, dairy, and fast food in the U.S. diet. J. Agric Food Chem 54: 463-467.

35. Saini RK, Nile SH, Park SW (2015) Carotenoids from fruits and vegetables: Chemistry, analysis, occurrence, bioavailability and biological activities. Food Res Int 76 : 735-824.
36. Jäpelt RB, Jakobsen $J$ (2013) Vitamin D in plants:areviewofoccurrence, analysis, and biosynthesis. Front Plant Sci 4: 136.

37. Pilz S, März W, Cashman KD, Kiely ME, Whiting SJ, et al. (2018) Rationale and plan for Vitamin D Food Fortification: A Review and Guidance Paper. Front Endocrinol 9: 373.

38. Blasiak J, Pawlowska E, Chojnacki J, Szczepanska J, Fila $M$, et al. (2020) Vitamin D in Triple-Negative and BRCA1DeficientBreast Cancer-implications for pathogenesisand therapy. Int J Mol Sci 21: 3670.

39. Costantini L, Magno S, Albanese D, et al. (2018) Characterization of human breast tissue microbiota from core needle biopsies through the analysis of multi hypervariable 16S-rRNA gene regions. Sci Rep 8: 16893.

40. Kim MK, Ahn SH, Son BH, Sung MK (2010) Plasma antioxidant concentration, not superoxide dismutase polymorphism, is associated with breast cancer risk in Korean women. Nutr Res 30: 705-713.

41. Kim JA, Choi R, Won H, Kim S, Choi HJ, et al. (2020) Serum Vitamin Levels and Their Relationships with Other Biomarkers in Korean Breast Cancer Patients. Nutrients 12: 2831.

42. Mangiarotti R, Danova M, Alberici R, Pellicciari C (1998) Alltrans retinoic acid (atra)-induced apoptosis is preceded by g1 arrest in human mcf-7 breast cancer cells. $\mathrm{Br} \mathrm{J}$ Cancer 77: 186-191.

43. Wu MJ, Kim MR, ChenYS, Yang JY, Chang CJ (2017) Retinoic acid directs breast cancer cell state changes through regulation of tet2-pkczeta pathway. Oncogene 36: 3193-3206.

44. Bernardo AR, Cosgaya JM, Aranda A, Jimenez Lara AM (2017) Pro-apoptotic signaling induced by Retinoic acid and dsRNAis under the control of Interferon Regulatory Factor-3 in breastcancer cells. Apoptosis 22: 920-932.

45. Bolis M, Paroni G, Fratelli M, Vallerga A, Guarrera L, et al. (2020) All-Trans Retinoic Acid Stimulates Viral Mimicry, Interferon Responses and Antigen Presentation in BreastCancer Cells. Cancers 12: 1169.

46. Phipps SM, Love WK, White T, Andrews LG, Tollefsbol TO, et al (2009) Retinoid-induced histone deacetylation inhibits telomerase activity in estrogen receptor-negative breast cancer cells. Anticancer Res 29: 4959-4964.

47. Ciolino HP, Dai Z, Nair V (2011) Retinol inhibits aromatase activity and expression in vitro. J Nutr Biochem 22: 522526.

48. Chen Q, Ross AC (2012) All-trans-retinoic acid and the glycolipid alphagalactosylceramide combined reduce breast tumor growth and lung metastasis in a 4T1 murine breast tumor model. Nutr Cancer 64: 1219-1227.

49. Sumantran VN, Zhang R, David S, Lee S, Wicha MS (2000) Differential Regulation of Apoptosis in Normal versus Transformed Mammary Epithelium by Lutein and Retinoic Acid. Cancer Epidemiol Biomarkers Prev 9: 257-263.

50. Shree GS, Prasad KY, Arpitha HS, Deepika UR, Kumar $\mathrm{KN}$, et al. (2017) $\beta$-carotene at physiologically attainable concentration induces apoptosis and down-regulates cell survival and antioxidant markers in human breast cancer (MCF-7) cells. Mol Cell Biochem 436: 1-12.

51. Saini RK, Keum Y-S, Daglia M, et al. (2020) Dietary carotenoids in cancer chemoprevention and chemotherapy: A review of emerging evidence. Pharmacol Res 157: 104830 
52. Cho SO, Kim MH, Kim H (2018) $\beta$-Carotene inhibits activation of NF-KB, activator protein- 1 , and STAT3 and regulates abnormal expression of some adipokines in 3T3L1 adipocytes. J Cancer Prev 23: 37-43.

53. Gong X, Marisiddaiah R, Zaripheh S, Wiener D, Rubin LP, et al. (2016) Mitochondrial $\beta$-carotene 9',10'oxygenase modulates prostate cancer growth via NF-KB inhibition: alycopeneindependent function. Mol Cancer Res 14: 966975.

54. Kim J, Park MK, Li WQ, Qureshi AA, Cho E, et al. (2019) Association of vitamin $A$ intake with cutaneous squamous cell carcinoma risk in the United States. JAMA Dermatol 155: $1260-1268$.

55. Kaegi E (1998) Unconventional therapies for cancer: 5. Vitamins $A, C$ and $E$. on behalf of the Task Force on Alternative Therapies of the Canadian Breast Cancer Research Initiative. CMAJ 158: 1157-1159.

56. Eliassen $\mathrm{AH}$, Hendrickson SJ, Brinton LA, Buring JE, Campos H, et al. (2012) Circulating carotenoids and risk of breast cancer: pooled analysis of eight prospective studies. J Natl Cancer Inst 104: 1905-1916.

57. He J, Gu Y, Zhang S (2018) Vitamin A. and Breast Cancer Survival: A Systematic Review and Meta-analysis. Clin Breast Cancer 18: 1389-1400.

58. Fiedor J, Burda K (2014) Potential role of carotenoids as antioxidants in human health and disease. Nutrients 6: 466488.

59. Shin MH, Holmes MD, Hankinson SE, Wu K, Colditz GA, et al. (2002) Intake of dairy products, calcium, and vitamin D and risk of breast cancer. J NatlCancer Inst 94: 1301-1311.

60. Vijay K, Sowmya PR-R, Arathi BP, Shilpa S, Shwetha HJ, et al. (2018) Low-dose doxorubicin with carotenoids selectively alters redox status and upregulates oxidative stress-mediated apoptosis in breast cancer cells. Food Chem Toxicol 118: 675-690.

61. Bohlke K, Spiegelman D, Trichopoulou A, Katsouyanni K, Trichopoulos D (1999) Vitamins A, C and E and the risk of breast cancer:results from a case-control study in Greece. $\mathrm{Br} J$ Cancer 79: 23-29.

62. FulanH, Changxing J, Baina WY, Wencui Z, Chunqing L, et al. (2011) Retinol, vitamins A, C, and E and breast cancer risk: a meta-analysis and meta-regression. Cancer Causes Control 22: 1383-1396.

63. Bakker MF, Peeters PHM,Klaasen VM, Bueno-de-Mesquita $\mathrm{HB}$, Jansen $\mathrm{EH}$, et al. (2016) Plasma carotenoids, vitamin $\mathrm{C}$, tocopherols, and retinol and the risk of breast cancer in the European Prospective Investigation into Cancer and Nutrition cohort. Am J Clin Nutr 103: 454-464.

64. Sun L, Yoshii Y, Miyagi K, Ishida A (1999) Proliferation inhibition of glioma cells by vitamin K2. No Shinkei Geka 27: 119-125.

65. Mamede AC, Tavares SD, Abrantes AM, Trindade J, Maia JM, et al. (2011) The Role of Vitamins in Cancer: A Review. Nutr Cancer 63: 479-494.

66. Lamson DW, Plaza SM (2003) The anticancer effects of vitamin K. Altern Med Rev 8: 303-318.

67. Noto $\mathrm{V}$, Taper HS, Jiang $\mathrm{YH}$, Janssens $\mathrm{J}$, Bonte $\mathrm{J}$, et al. (1989) Effects of sodium ascorbate (vitamin C) and 2-methyl-1,4-naphthoquinone (vitamin K3) treatment on human tumor cell growth in vitro. I. Synergism of combined vitamin $\mathrm{C}$ and $\mathrm{K} 3$ action. Cancer 63: 901-906.

68. Miyazawa K, Moriya S, Kokuba H, Hino H, Takano N, et al.
(2020) Vitamin K2 induces non-apoptotic cell death along with autophagosome formation in breast cancer cell lines. Breast Cancer 27: 225-235.

69. Gan L, CamarenaV, Mustafi S, Wang G (2019) Vitamin C Inhibits Triple-Negative Breast CancerMetastasis by A_ecting the Expression of YAP1 andSynaptopodin 2. Nutrients 11: 2997.

70. Vollbracht C, Schneider B, Leendert V, Weiss G, Auerbach L, et al. (2018) Intravenous vitamin $C$ administration improves quality of life in breast cancer patients during chemo-/ radiotherapy and aftercare: Results of a retrospective, multicentre, epidemiological cohort study in Germany. In Vivo 25: 983-990.

71. Carr AC, Vissers MCM, Cook J (2014) Relief from cancer chemotherapy side effects with pharmacologic vitamin $C$. N. Z. Med J 127: 66-70.

72. Zeng J, Wang K, Ye F, Lei L, Zhou Y, et al. (2019) Folate intake and the risk of breast cancer: an up-to-date metaanalysis of prospective studies. Eur J Clin Nutri 73: 1657-1660.

73. Harris HR, Orsini N, Wolk A (2014) Vitamin C and survival among women with breast cancer: A Meta-analysis. Eur J Cancer 50: 1223-1231.

74. Zeng LH, Wang QM, Feng LY, Ke YD, Xu QZ, et al. (2019) High-dose vitamin $C$ suppresses the invasion and metastasis of breast cancer cells via inhibiting epithelial mesenchymal transition. Onco Targets Ther 12: 74057413.

75. Afam IOJ, Silungwe H, Takalani T, Omolola AO, Udeh HO, et al. (2021) Antioxidant-rich natural fruit and vegetable products and human health. Inter J Food Propert 24: 41-67.

76. Jiang Q (2017) Natural forms of vitamin $E$ as effective agents for cancer prevention and therapy. Adv Nutr 15: 850-867.

77. Shah SJ, Sylvester PW (2005) Tocotrienolinduced cytotoxicity is unrelated to mitochondrial stress apoptotic signaling in neoplastic mammary epithelial cells. Biochem Cell Biol 83: 86-95.

78. Nesaretnam K, Stephen R, Dils R, Darbre P (1998) Tocotrienols inhibit the growth of human breast cancer cells irrespective of estrogen receptor status. Lipids 33: 461-469.

79. Yu W, Simmons-Menchaca M, Gapor A, Sanders BG, Kline K (1999) Induction of apoptosis in human breast cancer cells by tocopherols and tocotrienols. Nutr Cancer 33: 2632.

80. McIntyre BS, Briski KP, Gapor A, Sylvester PW (2000) Antiproliferative and apoptotic effects of tocopherols and tocotrienols on preneoplastic and neoplastic mouse mammary epithelial cells (44544). Proc Soc Exp Biol Med 224: $292-301$

81. Kline K, Yu W, Sanders BG (2004) Vitamin E and Breast Cancer1. J Nutr 134: 3458S-3462S.

82. Malafa MP, Neitzel LT (2000) Vitamin E Succinate Promotes Breast Cancer Tumor Dormancy. J Surg Res 93: 163-170.

83. Yu W, Sanders BG, Kline K (2003) RRR-a-tocopheryl succinate-induced apoptosis of human breast cancer cells involves Bax translocation to mitochondria. Cancer Res 63: 2483-2491.

84. Sylvester P, Mclntyre B, Gapor A, Briski KP(2001) Vitamin $E$ inhibition of normal mammary epithelial cell growth is associated with a reduction in protein kinase $\mathrm{C} \alpha$ activation. Cell Prolif 34: 347-357. 
85. Abraham A, Kattoor AJ, Saldeen T, Mehta JL (2019) Vitamin $E$ and its anticancer effects. Crit Rev Food Sci Nutr 59: $2831-2838$

86. Lajous M, Romieu I, Sabia S, Boutron-Ruault MC, ClavelChapelon F (2006) Folate, vitamin B12 and postmenopausal breast cancer in a prospective study of French women. Cancer Causes Control 17: 1209-1213.

87. Hu F,Wu Z, Li G, Teng C, Liu Y, et al. (2015) The plasma level of retinol, vitamins $A, C$ and $\alpha$-tocopherol could reduce breast cancer risk? A meta-analysis and meta-regression. $J$ Cancer Res Clin Oncol 141: 601-614.

88. Torun M, Akgul S, Sargin H (1995) Serum vitamin E level in patients with breast cancer. J Clin Pharm Ther 20: 173-178.

89. Ben-Chioma AE, Elekima I (2018) Evaluation of Vitamin $E$ and Selenium Levels inBreast Cancer Patients in Port Harcourt Metropolis, Nigeria. J Advan Medici Medic Res 28: 1-7.

90. Turley JM, Tao Fu, Ruscetti FW, Mikovits JA, Bertolette DC et al. (1997) Vitamin E Succinate Induces Fas-mediated Apoptosis in Estrogen Receptor Negative Human Breast Cancer Cells. Cancer Res 57: 881-890.

91. Sigounas G, Anagnostou A, Steiner M (1997) DI-aTocopherol induces apoptosis in erythroleukemia, prostate, and breast cancer cells. Nutr Cancer 28: 30-35.

92. Godazandeh G, Shahram Al, Motlaq TM, Sahebnasagh A, Bazi A (2021) The comparison of the effect of flaxseed oil and vitamin $E$ on mastalgia and nodularity of breast fibrocystic: a randomized double blind clinical trial. J Pharm Health Care Sci 7: 4.

93. Theriault A, Chao JT, Wang Q, Gapor A, Adeli K (1999) Tocotrienol: a review of its therapeutic potential. Clin Biochem 32: 309-319.

94. Aung TT, Chandana SR, D'Silva KJ, et al. (2009) The role of vitamin D in breast cancer. Oncol Rev 3: 19-25.

95. John EM, Schwartz GG, Dreon DM, Koo J (1999) Vitamin $\mathrm{D}$ and Breast Cancer Risk: The NHANES I Epidemiologic Follow-up Study, 1971-1975 to 1992. National Health and Nutrition Examination Survey. Cancer Epidemiol Biomarkers Prev 8: 399-406.

96. Garland CF, Gorham ED, Mohr SB, Grant WB, Giovannucci EL, et al. (2007) Vitamin D and prevention of breast cancer: pooled analysis. J Steroid Biochem Mol Biol 103: 708-711.

97. Chen P, Hu P, Xie D, Qin Y, Wang F, et al. (2010) Metaanalysis of vitamin $\mathrm{D}$, calcium and the prevention of breast cancer. Breast Cancer Res Treat 121: 469-477.

98. Mohr SB, Gorham ED, Kim J, Hofflich H, Garland CF, et al (2014) Meta-Analysis of Vitamin D Sufficiency for Improving Survival Of Patients With Breast Cancer. Anticancer Res 34: 1163-1166.

99. Stoll F, Akladios CY, Mathelin C, et al. (2013) Vitamin D and breast cancer: Is there a link? Gynecol Obstet Fertil 41: $242-250$.

100. Shekarriz-Foumani R, Khodaie F (2016) The correlation of plasma 25-hydroxyvitamin $D$ deficiency with risk of breast neoplasms: A systematic review. Iran J Cancer Prev 9: e4469.

101. Bilinski K, Boyages J (2013) Association between 25-hydroxyvitamin D concentration and breast cancer risk in an Australian population: an observational case-control study. Breast Cancer Res Treat 137: 599-607.

102. Park S, Lee DH, Jeon JY, Ryu J, Kim S, et al. (2015)
Serum 25-hydroxyvitamin D deficiency and increased risk of breast cancer among Korean women: a case-control study. Breast Cancer Res Treat 152: 147-154.

103. Al-Azhri J, Zhang Y, Bshara W, Zirpoli G, McCann SE, et al. (2016) Tumor Expression of Vitamin D Receptor and Breast Cancer Histopathological Characteristics and Prognosis. Clin Cancer Res 23: 97-103.

104. Welsh J, Wietzke JA, Zinser GM, Byrne B, Smith K, et al. (2003) Vitamin D-3 Receptor as a Target for Breast Cancer Prevention. JNutr 133: 2425S-2433S.

105. Welsh J (2004) Vitamin D and breast cancer: Insights from animal models. Am J Clin Nutr 80: 1721S-1724S.

106. Cui Y, Rohan TE (2006) Vitamin D, Calcium, and Breast Cancer Risk: A Review. Cancer Epidemiol Biomarkers Prev 15: 1427-1437.

107. Garland CF, Garland FC, Gorham ED, Lipkin M, Newmark $\mathrm{H}$, et al. (2006) The Role of Vitamin D in Cancer Prevention. Am J Public Health 96: 252-261.

108. KrishnanAV, Feldman D (2011) Mechanisms of the AntiCancer and Anti-Inflammatory Actions of Vitamin D. Annu Rev Pharmacol Toxicol 51: 311-336.

109. Kim Y, Je $Y$ (2014) Vitamin D intake, blood $25(\mathrm{OH})$ $\mathrm{D}$ levels, and breast cancer risk or mortality: A metaanalysis. Br J Cancer 110: 2772-2784.

110. Narvaez CJ, Matthews D, LaPorta E, Simmons KM, Beaudin S, et al. (2014) The impact of vitamin D in breast cancer:genomics, pathways, metabolism. Front Physiol 5: 213.

111. Tavera-Mendoza LE, Westerling T, Libby E, Marusky A, Cato L, et al. (2017) Vitamin D receptor regulates autophagy in the normal mammary gland and in luminal breast cancer cells. Proc Natl Acad Sci 114: E2186-E2194.

112. Patel PS, Franky D, Shaha FD, Patel KR, Gokani RA, et al. (2020) Clinical significance of serum 25 hydroxyvitamin $\mathrm{D}$ in breast cancer: An Indian scenario. J Steroid Biochem Mol Biol 202: 105726.

113. Autier P, Boniol M, Pizot C, Mullie P (2014) Vitamin D status and ill health: A systematic review. Lancet Diabetes Endocrinol 2: 76-89.

114. Zhang $X$, Harbeck $N$, Jeschke U, Doisneau-Sixou S (2017) Influence of vitamin D signaling on hormone receptor statusand HER2 expression in breast cancer. $J$ Cancer Res Clin Oncol 143: 1107-1122.

115. Deeb KK, Trump DL, Johnson CS (2007) Vitamin D signalling pathways in cancer: potential for anticancer therapeutics. Nat Rev Cancer 7: 684-700.

116. Kulling PM, Olson KC, Olson TL, Feith DJ, Loughran TP (2017) Vitamin D in hematological disorders and malignancies. Eur J Haematol 98: 187-197.

117. Song D, Deng Y, Liu K, Zhou L, Li N, et al. (2019) Vitamin $\mathrm{D}$ intake, blood vitamin $\mathrm{D}$ levels, and the risk of breast cancer: a dose-response meta-analysis of observational studies. AGING 11: 12708-12732.

118. Janowsky EC, Lester GE, Weinberg CR, Millikan RC, Schildkraut JM, et al. (1999) Association between low levels of 1,25-dihydroxyvitamin Dand breast cancer risk. Public Health Nutri 2: 283-291.

119. HossainS, Beydoun MA, Beydoun HA, Chen $X$, Zonderman $A B$, et al. (2019) Vitamin D and breast cancer: A systematic review and meta-analysis of observational studies. Clin Nutr ESPEN 30: 170-184. 
120. ShiraziL, Almquist M, Borgquist S, Malm J, Manjer J (2016) Serum vitamin D (25OHD3) levels and the risk of different subtypes of breast cancer: A nested case- control study. The Breast 28: 184-190.

121. Bertone-Johnson ER, Chen WY, Holick MF, Hollis BW, Colditz GA, et al. (2005) Plasma 25-hydroxyvitamin D and 1,25- dihydroxyvitamin $D$ and risk ofbreast cancer. Cancer Epidemiol Biomarkers Prev 14: 1991-1997.

122. Garland CF, Gorham ED, Mohr SB, Garland FC (2009) Vitamin $D$ for cancer prevention: global perspective. Ann Epidemiol 19: 468-483.

123. Kim SJ, Zuchniak A, Sohn KJ, Lubinski J, Demsky R, et al. (2016) Plasma folate, vitamin B-6, and vitamin B-12 and breast cancer risk in BRCA1- and BRCA2-mutation carriers: a prospective study. Am J Clin Nutr 104: 671677.

124. Stevens VL, McCullough ML, Pavluck AL, Talbot JT, Feigelson HS, et al. (2007) Association of polymorphisms in one-carbon metabolism genes and postmenopausal breast cancer incidence. Cancer Epidemiol Biomarkers Prev 16: 1140-1147.

125. Bassett JK, Baglietto L, Hodge AM, Severi G, Hopper JL, et al. (2013) Dietary intake of B vitamins and methionine and breast cancer risk. Cancer Causes Control 24: 15551563.

126. Shrubsole MJ, Jin F, Dai Q, Shu X-O, Potter JD, et al. (2001) Dietary Folate Intake and Breast Cancer Risk: Results from the Shanghai Breast Cancer Study. Cancer Res 61: 7136-7141.

127. Xu X, Gammon MD, Wetmur JG, Bradshaw PT, Teitelbaum SL, et al. (2008)B-Vitamin Intake, OneCarbon Metabolism, and Survival in a Population-Based Study of Women with Breast Cancer. Cancer Epidemiol Biomarkers Prev 17: 2109-2116.

128. Yu L, Tan Y, Zhu L (2017) Dietary vitamin B2 intake and breast cancer risk: a systematic review and meta-analysis. Arch Gynecol Obstet 295: 721-729.

129. Razeghian E, Mohammed B, Nemati AH, et al. (2020) Folic acid, vitamin B6, B12, and breast cancer incidence. Spring 5: 4-6.

130. Ren X, Xu P, Zhang D, Liu K, Song D, et al. (2020) Association of folate intake and plasma folate level with the risk of breast cancer: A dose-response meta-analysis of observational studies. AGING 12: 21355-21375.
131. Egnell M, Fassier $P$, Lécuyer L, Zelek L, VassonMP, et al. (2017) B-Vitamin Intake from Diet and Supplements andBreast Cancer Risk in Middle-AgedWomen: Results from the Prospective Nutri Net-Santé Cohort. Nutrients 9: 488.

132. Agnoli C, Grioni S, Krogh V, et al. (2016) Plasma Riboflavin and Vitamin B-6, but Not Homocysteine, Folate, or Vitamin B-12, Are Inversely Associated with Breast Cancer Risk in the European Prospective Investigation into Cancer and Nutrition-Varese Cohort 1-3. The J NutriNutrition Epidemiol 1-8.

133. Lurie G, Wilkens LR, Shvetsov YB, Ollberding NJ, Franke AA, et al. (2012) Prediagnostic Plasma Pyridoxal 50-Phosphate (Vitamin B6) Levels and Invasive Breast Carcinoma Risk: Multiethnic Cohort 9.

134. Zhang SM, Willett WC, Selhub J, Hunter DJ, Giovannucci EL, et al. (2003) Plasma folate, vitamin B6, vitamin B12, homocysteine, and risk of breast cancer. J Natl Cancer Inst 95: 373-380.

135. Zhang SM, Cook NR, Albert CM, Gaziano JM, Buring JE, et al. (2008) Effect of Combined Folic Acid, Vitamin B6, and Vitamin B12 on Cancer Risk: Results from a Randomized Trial. JAMA 300: 2012-2021.

136. Shrubsole MJ, Shu XO, Li HL, Cai H, Yang G, et al. (2011) Dietary B Vitamin and Methionine Intakes and Breast Cancer Risk Among Chinese Women. Am J Epidemiol 173: 1171-1182.

137. Lin J, Lee IM, Cook NR, Selhub J, Manson JE, et al. (2008) Plasma folate, vitamin B-6, vitamin B-12, and risk of breast cancer in women. Am J Clin Nutr 87: 734-743.

138. Matsubara K, Komatsu S, Oka T, Kato N (2003) Vitamin B6-mediated suppression of colon tumorigenesis, cell proliferation, and angiogenesis. J Nutr Biochem 14: 246250.

139. Yang D, Baumgartner RN, Slattery ML, Wang C, Giuliano $A R$, et al. (2013) Dietary intake of folate, B-vitamins and methionine and breast cancer risk among Hispanic and non-Hispanic white women. PLoS One 8: 54495.

140. Liu Y, Zhou L-S, Xu X-M, Deng L-Q, Xiao Q-K (2013) Association of Dietary Intake of Folate, Vitamin B6 and B12 and MTHFR Genotype with Breast Cancer Risk. Asian Pac J Cancer Prev 14: 5189-5191. 